\title{
Preparation of Battery-Grade Lithium Carbonate with Lithium-Containing Desorption Solution
}

\author{
Zheng-Guo $\mathrm{Xu}{ }^{1}$ and Shu-Ying Sun ${ }^{1,2, *}$ \\ 1 National Engineering Research Center for Integrated Utilization of Salt Lake Resource, School of Resources \\ and Environmental Engineering, East China University of Science and Technology, Shanghai 200237, China; \\ xzget1@163.com \\ 2 Joint International Laboratory for Potassium and Lithium Strategic Resources, School of Resources and \\ Environmental Engineering, East China University of Science and Technology, Shanghai 200237, China \\ * Correspondence: shysun@ecust.edu.cn
}

check for updates

Citation: Xu, Z.-G.; Sun, S.-Y. Preparation of Battery-Grade Lithium Carbonate with Lithium-Containing Desorption Solution. Metals 2021, 11, 1490. https://doi.org/10.3390/ met11091490

Academic Editors: Rahul Ram and Mark I. Pownceby

Received: 4 August 2021

Accepted: 17 September 2021

Published: 19 September 2021

Publisher's Note: MDPI stays neutral with regard to jurisdictional claims in published maps and institutional affiliations.

Copyright: (C) 2021 by the authors. Licensee MDPI, Basel, Switzerland. This article is an open access article distributed under the terms and conditions of the Creative Commons Attribution (CC BY) license (https:// creativecommons.org/licenses/by/ $4.0 /)$.

\begin{abstract}
In this study, a process for preparing battery-grade lithium carbonate with lithium-rich solution obtained from the low lithium leaching solution of fly ash by adsorption method was proposed. A carbonization-decomposition process was carried out to remove impurities such as iron and aluminum. First, primary $\mathrm{Li}_{2} \mathrm{CO}_{3}$ was treated by $\mathrm{CO}_{2}$ to get the more soluble bicarbonates. The decomposition of $\mathrm{LiHCO}_{3}$ produced insoluble $\mathrm{Li}_{2} \mathrm{CO}_{3}$ at $90{ }^{\circ} \mathrm{C}$ And $\mathrm{Li}_{2} \mathrm{CO}_{3}$ was smashed by air stream pulverization. The final precipitation yielded a high purity $(99.6 \%)$ and homogeneous $\mathrm{Li}_{2} \mathrm{CO}_{3}$. Some factors affecting production efficiency were investigated. The results showed that a liquid-solid ratio of 25:1, a carbonization temperature of $25^{\circ} \mathrm{C}$, an air velocity of $2 \mathrm{~L} / \mathrm{min}$, and a stirring speed of $400 \mathrm{rpm}$; a decomposition temperature of $90^{\circ} \mathrm{C}$ and a stirring speed of $400 \mathrm{rpm}$, a molar ratio of EDTA to Ca 2:1; an air pressure of $0.3 \mathrm{MPa}$ and hot water washing precipitate (L/S mass ratio 2:1) promoted ions removal.
\end{abstract}

Keywords: lithium carbonate; carbonation; decomposition; battery-grade; air stream pulverization

\section{Introduction}

Lithium has become one of the most significant resources around the world due to the fast-growing lithium-ion battery demand nowadays. Lithium carbonate is used in many industries as the initial raw material. Especially in the field of new energy, battery-grade lithium carbonate is required, which has higher requirements for the lithium carbonate process.

At present, the preparation of lithium carbonate from salt lake brine is usually by the evaporation-crystallization-precipitation method. Among that the development of carbonate precipitation is relatively mature and is suitable for brines with a low $\mathrm{Mg} / \mathrm{Li}$ ratio. Various additives (such as sodium bicarbonate and oxalic acid [1,2]), ultrasonic waves [3], and reaction systems [4,5] were studied to discuss the influence on crystal size and morphology. Sun [6] made a systematic study on the crystallization process of lithium carbonate and prepared lithium carbonate products with various purity, granularity, and morphology. Three industrial routes of $\mathrm{Li}_{2} \mathrm{CO}_{3}$ recrystallization, $\mathrm{LiHCO}_{3}$ thermal decomposition reaction crystallization, and $\mathrm{LiOH}+\mathrm{CO}_{2}$ gas-liquid crystallization were used to prepare high-purity lithium carbonate products with purity higher than $99.9 \%$.

The industrial production of battery-grade lithium carbonate generally does not directly carry out from ore and brine, because these principles contain high impurities thus it is difficult to guaranteed purity [7-10]. Therefore, industrial-grade lithium carbonate is obtained from different lithium resources through different separation processes and then purified to obtain battery-grade lithium carbonate [11-13]. Carbonization is one of the more commonly used methods which mainly reacts lithium carbonate with carbon dioxide and water to generate lithium bicarbonate with greater solubility [14]. Generally, ion-exchanged 
resin is used to remove calcium and magnesium impurities with the inevitable loss of lithium [15].

In recent years, with the development of high-value added utilization of solid waste, the recovery of lithium, gallium, and other elements in fly ash has been on the agenda. In previous studies, we proposed a method of extracting lithium from fly ash with a lithium content of $0.25 \mathrm{mg} / \mathrm{g}$ and obtained a lithium-containing desorption solution [16]. This research was based on the solution to design a battery-grade lithium carbonate process. It was realized that fly-ash was another high-value source for lithium extraction. Compared with traditional technologies, iron, aluminum, and silicon can be removed effectively from lithium carbonate using this method. Meanwhile, the resin adsorption process of impurity ions can be eliminated. The strategy is effective to control product granularity to meet the requirements of battery-grade lithium carbonate. The effects of various factors on the yield and purity of the final lithium carbonate product were investigated, and a set of feasible process schemes were provided.

\section{Methods}

\subsection{Materials and Chemicals}

Lithium-containing desorption solution was obtained from the low lithium leaching solution of fly ash by the adsorption method [16] with a concentration shown in Table 1. The main impurity ions in the desorption solution are sodium, iron, aluminum, and silicon. The concentration of lithium is about $13.59 \mathrm{~g} / \mathrm{L}$. All chemicals in the study were analytical grade.

Table 1. Main compositions of the lithium-containing desorption solution.

\begin{tabular}{ccccccc}
\hline & $\mathbf{L i}$ & $\mathbf{N a}$ & $\mathbf{A l}$ & $\mathbf{K}$ & $\mathbf{C a}$ & $\mathbf{F e}$ \\
\hline $\mathrm{g} / \mathrm{L}$ & 13.59 & 70.04 & 0.0328 & 1.006 & 0.3172 & 0.0366 \\
\hline
\end{tabular}

\subsection{Experimental Equipment and Analytical Instruments}

A constant temperature water bath, a DZF-6090 vacuum drying oven, an AR2140 OHAUS precision analytical balance, an S10-3 constant temperature magnetic stirrer, a PHSJ-3F laboratory $\mathrm{pH}$ meter, an ARCOS FHS12 inductively coupled plasma emission spectrometer, a MASTERSIZER 2000 laser particle size instrument (Malvern Instruments Ltd, Malvern, UK), and an S-3400N Scanning Electron Microscope (Hitachi Corporation of Japan, Tokyo, Japan) were used in this study.

\subsection{Methods}

Figure 1 outlined the major steps involved in the production of battery-grade $\mathrm{Li}_{2} \mathrm{CO}_{3}$. The lithium-containing desorption solution was concentrated first, and the saturated sodium carbonate solution was added to obtain a primary lithium carbonate product with purity as shown in Table 2 . The optimal reaction conditions were reported by recent research [17]: a reaction temperature of $90^{\circ} \mathrm{C}$, the dosage of sodium carbonate was 1.1 times the theoretical reaction dosage, a feed rate of $17 \mathrm{~mL} / \mathrm{min}$, and a stirring rate of $200 \mathrm{rpm}$. Hot water $\left(90^{\circ} \mathrm{C}\right)$ and ethanol were used to remove sodium ions.

Second, at different temperatures $\left(25,30,35,40,45^{\circ} \mathrm{C}\right)$, the primary lithium carbonate product was soaked in water with a liquid-solid ratio $(10,20,30,40,50)$, then $\mathrm{CO}_{2}(99 \%)$ was bubbled into the slurry with different flow rate $(1.0,1.5,2.0,2.5,3.0 \mathrm{~L} / \mathrm{min})$. And the $\mathrm{Li}_{2} \mathrm{CO}_{3}$ was converted to soluble $\mathrm{LiHCO}_{3}$. The lithium bicarbonate solution was obtained by filtration.

Finally, the lithium bicarbonate solution was added to the reactor and heated at a constant temperature $\left(60,70,80,90^{\circ} \mathrm{C}\right)$ in a water bath. After the reaction, the solids were washed twice with hot water and dried in an oven. Then the air stream pulverization was used to treat the high purity lithium carbonate. 


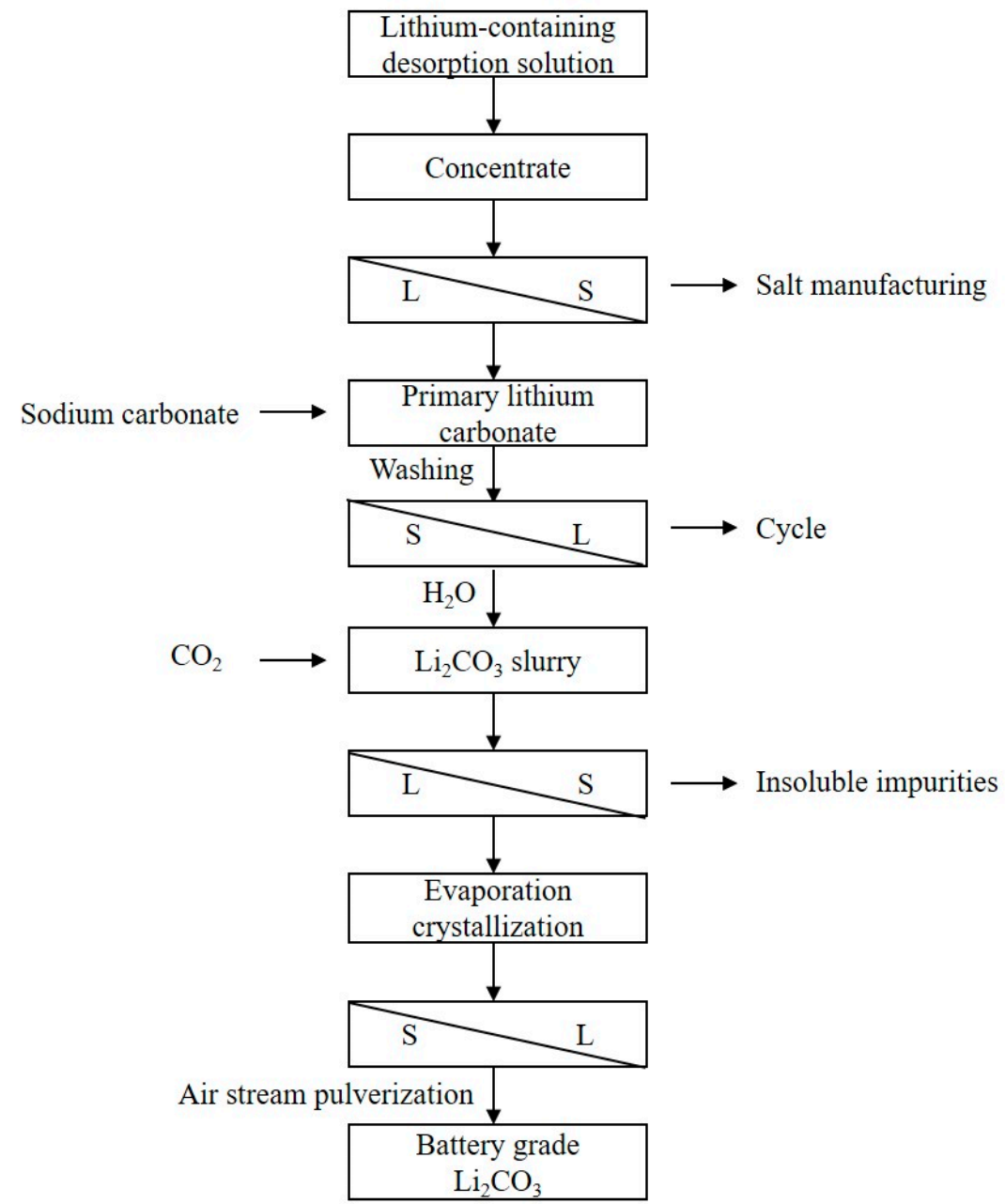

Figure 1. Flowsheet developed for the recovery of battery-grade $\mathrm{Li}_{2} \mathrm{CO}_{3}$ from the lithium-containing desorption solution.

Table 2. Impurity content of primary lithium carbonate products.

\begin{tabular}{cccccc}
\hline $\mathbf{L i}_{2} \mathbf{C O}_{3}$ & $\mathbf{N a}$ & $\mathbf{A l}$ & $\mathbf{K}$ & $\mathbf{C a}$ & $\mathbf{F e}$ \\
\hline $92.21 \%$ & $4.213 \%$ & $0.019 \%$ & $0.049 \%$ & $0.411 \%$ & $0.042 \%$ \\
\hline
\end{tabular}

\section{Results and Discussion}

\subsection{Washing Process of Products}

Special attention was paid to the effect of the washing process, and the results are shown in Figure 2. The washing process mainly removes sodium from the product. Water has a higher impurity removal efficiency than ethanol, but at the same time, the lithium loss is higher. It can be due to the lithium carbonate is more soluble in water than ethanol. When using water as a detergent, the content of impurities did not change significantly with the increase in washing times. But at the same time, the lithium loss increased continuously. It can be seen that there was a sudden increase in sodium after the fourth washing. It might be due to the impurities that have been removed completely while lithium carbonate was still being lost. 

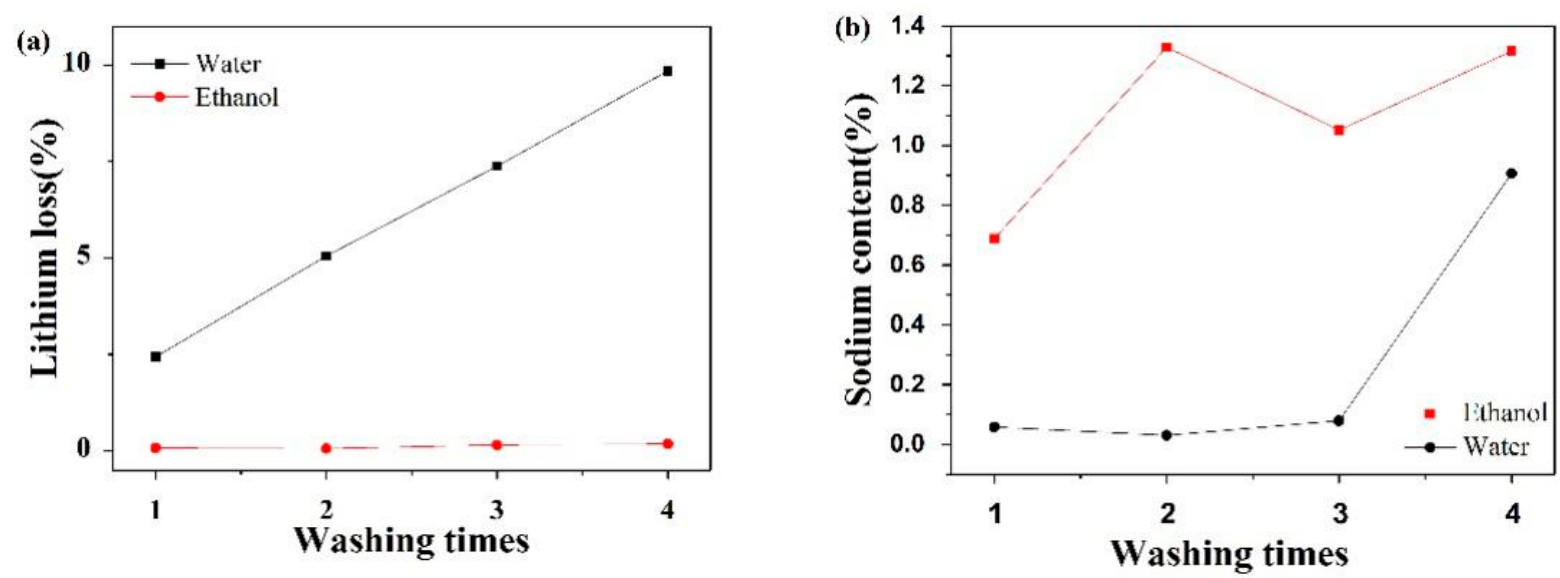

Figure 2. Washing process of water and ethanol: (a) lithium loss; (b) sodium content.

\subsection{Conversion of Impurities during Carbonization Process}

The concentration of impurities in the solution after carbonization was measured as shown in Figure 3. It can be seen that the concentration of impurities in the solution generally increased first and then decreased with time. The change of calcium ion concentration was particularly obvious, which may be due to calcium carbonate and lithium carbonate have the same properties and react with carbon dioxide. And calcium bicarbonate is easy to decompose at room temperature, resulting in a precipitation reaction. However, $\mathrm{Fe}_{2} \mathrm{CO}_{3}$ and $\mathrm{Al}_{2} \mathrm{CO}_{3}$ did not react with carbon dioxide at experimental temperatures. The impurities dissolve slightly during the process of slurring. But the precipitation reaction of $\mathrm{Fe}^{3+}$ and $\mathrm{Al}^{3+}$ occurs with the decrease of $\mathrm{pH}$ from 12 to 7 during the carbonization process [5].

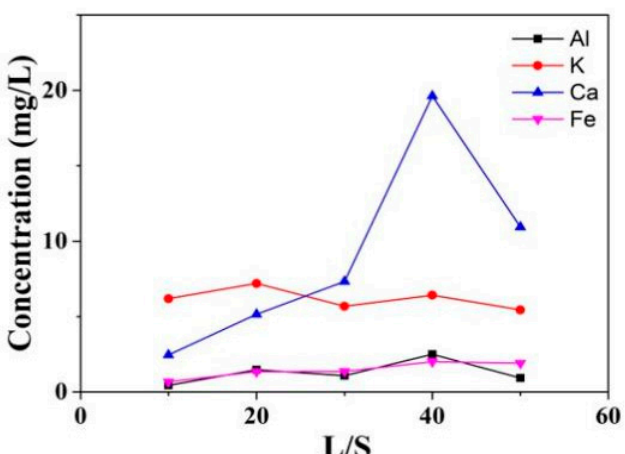

(a)

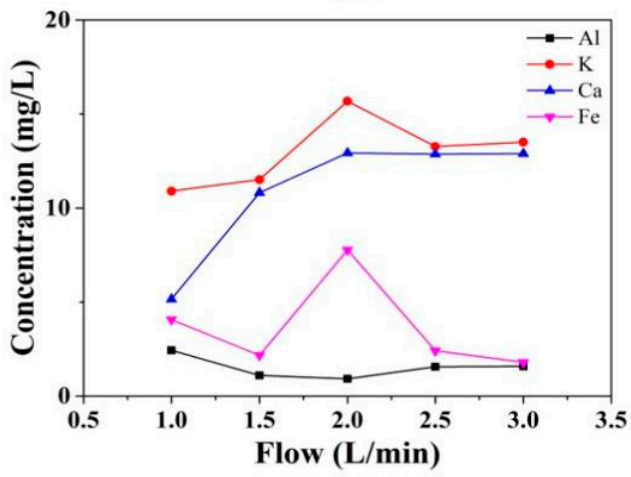

(c)

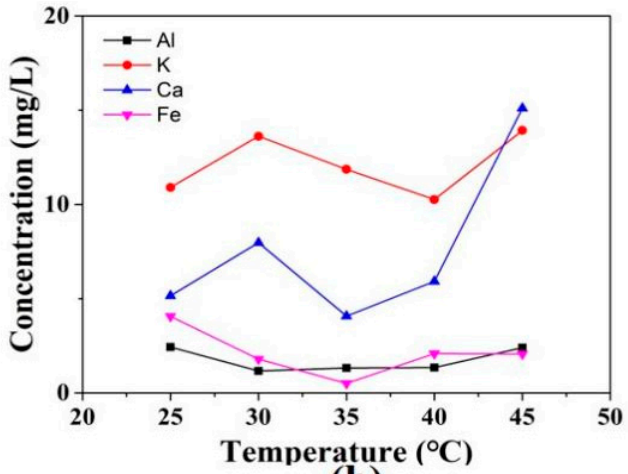

(b)

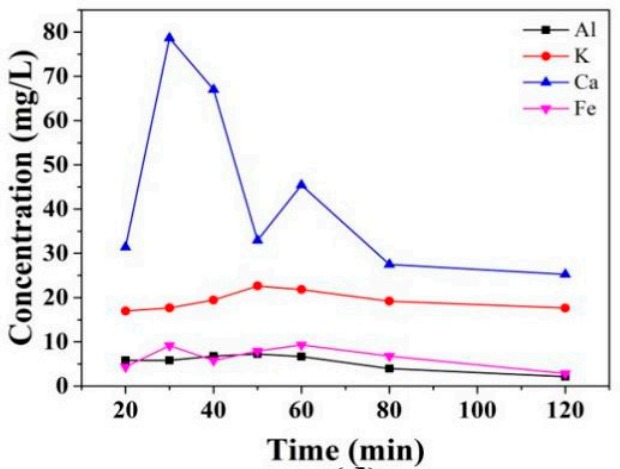

(d)

Figure 3. Effect of L/S (a) temperature (b) flow rate (c) time (d) on the concentration of impurities [liquid-solid ratio $=20$, temperature $=25^{\circ} \mathrm{C}$, flow rate of $\mathrm{CO}_{2}=3 \mathrm{~L} / \mathrm{min}$ ]. 


\subsection{Optimization of Carbonization Process}

In this study, the liquid-solid ratio $(\mathrm{mL} / \mathrm{g})$ refers to the ratio of the volume of deionized water and the mass of solid lithium carbonate. The effects of different liquid-solid ratios on carbonization reaction rates were studied. The conversion rate could be calculated as follows:

$$
\varphi=\frac{C V / 13.88 \times 73.89}{W} \times 100 \%
$$

where $C$ is the concentration of $\mathrm{Li}^{+}$in the solution $(\mathrm{mg} / \mathrm{L}), V$ is the volume of the solution $(\mathrm{L}), W$ is the Initial mass of lithium carbonate $(\mathrm{mg})$.

As can be seen from Figure 4, the conversion rate of lithium carbonate increased as the liquid-solid ratio increased. It can be explained that with an increase in the liquid-solid ratio, the bulk concentration of the slurry mixture decreased, which reduces the diffusion resistance in the liquid phase and at the liquid-solid boundary. On the other hand, as the solid concentration decreased, the slurry density and the friction between phases decreased, so that the total interface area of the reaction and the mass transfer rate increased [11]. The more fully lithium carbonate is in contact with carbon dioxide, the faster the reaction rate will be. As can be seen, the conversion rate was only $40 \%$ at a liquid-solid ratio of $10 \mathrm{~mL} / \mathrm{g}$. It might be that the solubility limit of lithium bicarbonate in an aqueous solution was reached, and the reaction could not proceed anymore.

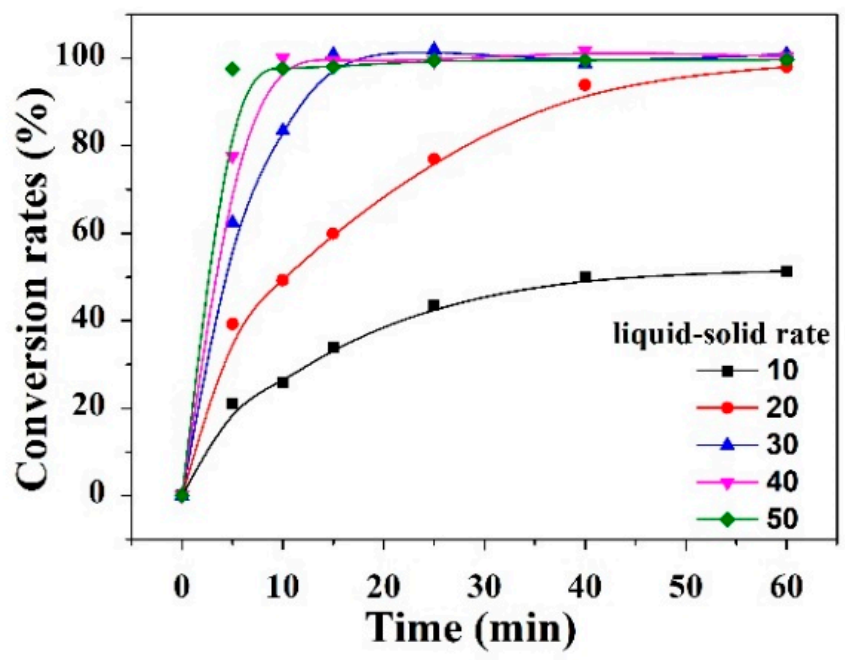

Figure 4. Effect of liquid-solid ratio on carbonization reaction [temperature $=25{ }^{\circ} \mathrm{C}$, flow rate of $\left.\mathrm{CO}_{2}=3 \mathrm{~L} / \mathrm{min}\right]$.

The conversion rate of lithium carbonate at different temperatures is shown in Figure 5. The carbonization process is controlled by mass transfer and reaction, in which mass transfer is the main control process [18]. The dissolution rates of lithium carbonate and carbon dioxide decreased with the increase in temperature, resulting in the decrease of mass transfer efficiency and the increase in reaction rate. On the other hand, lithium bicarbonate will be decomposed at high temperatures. Thus, as the temperature increased, the concentration of lithium at the reaction endpoint decreased, which means that the conversion rate gradually decreases. 


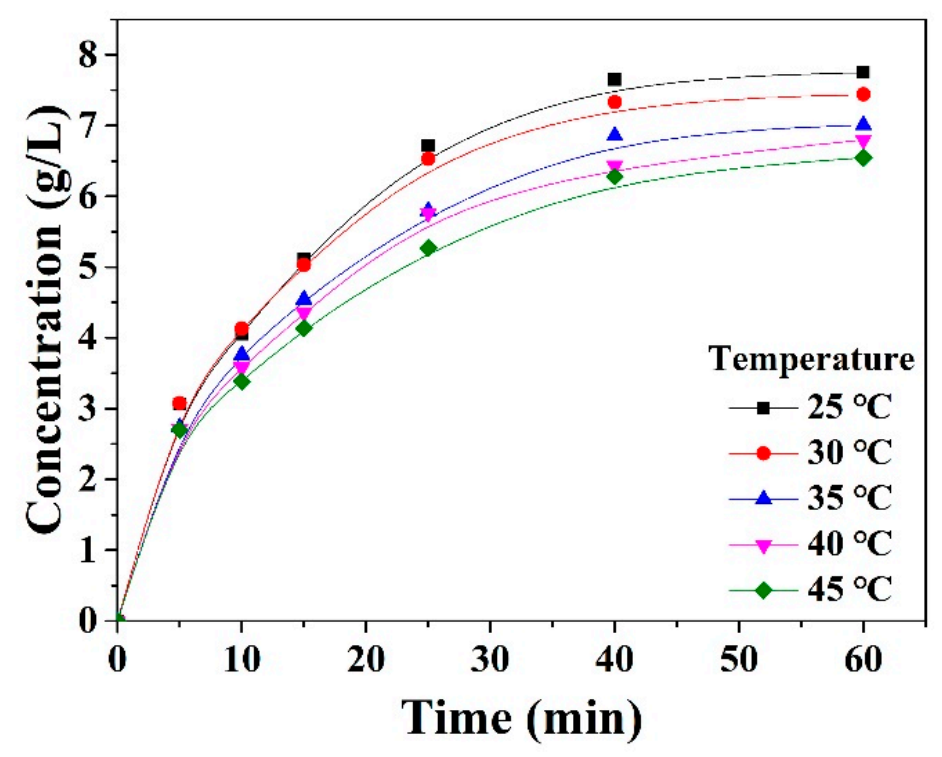

Figure 5. Effect of temperature on carbonization reaction [liquid-solid ratio $=20$, flow rate of $\left.\mathrm{CO}_{2}=3 \mathrm{~L} / \mathrm{min}\right]$.

As can be seen from Figure 6, with increasing the flow rate of $\mathrm{CO}_{2}$, the carbonation reaction rate was accelerated. It might be due to the volume mass transfer coefficient increased with the increase in $\mathrm{CO}_{2}$ flow rate. Similarly, these results were consistent with most studies in that using a high flow rate can enhance $\mathrm{Li}_{2} \mathrm{CO}_{3}$ dissolution in $\mathrm{CO}_{2}$-water solution [19]. However, it is not difficult to find that, with the increase in $\mathrm{CO}_{2}$ flow rate, the ventilation volume increased significantly within the same period, but the utilization rate of $\mathrm{CO}_{2}$ decreased relative to the volume. Thus, it is not appropriate to use an excessively high flow rate in industrial applications, and a previous study reported that increasing the pressure may improve the effective utilization rate of $\mathrm{CO}_{2}$.

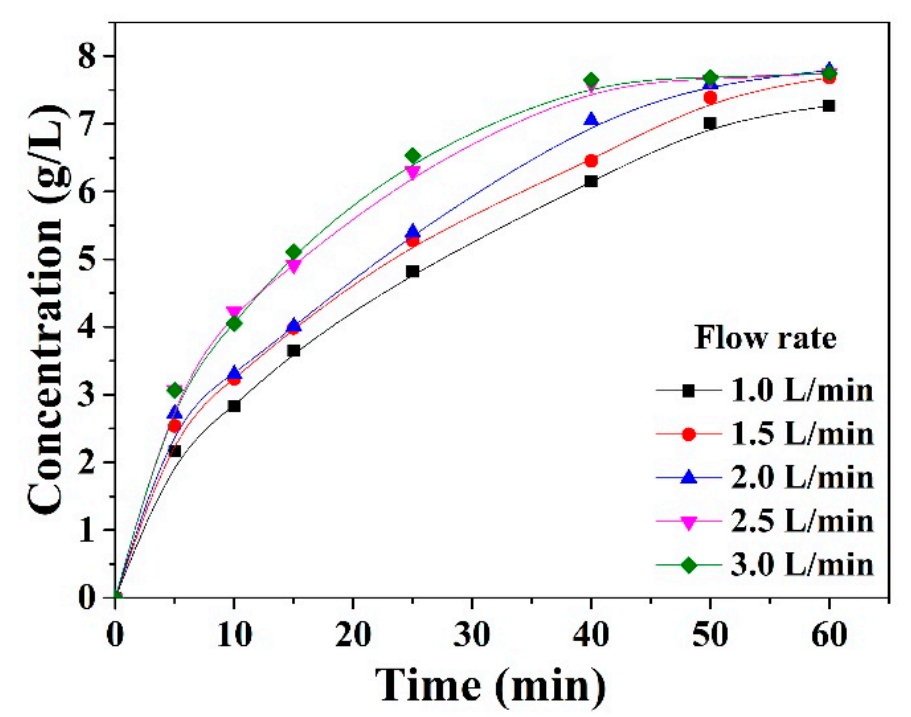

Figure 6. Effect of flow rate on carbonization reaction [liquid-solid ratio $=20$, temperature $=25^{\circ} \mathrm{C}$ ].

The $\mathrm{pH}$ of the reaction system at different time intervals was shown in Figure 7. It was noticed that during the carbonation process the $\mathrm{pH}$ of the solution started at about 11.85 and reached about 7.5 in the end, it can be seen that the acidity of the solution increased during carbonation. Finally, all $\mathrm{Li}_{2} \mathrm{CO}_{3}$ was converted to soluble $\mathrm{LiHCO}_{3}$. Therefore, the progress of the reaction can be accounted for by the variation of $\mathrm{pH}$. 


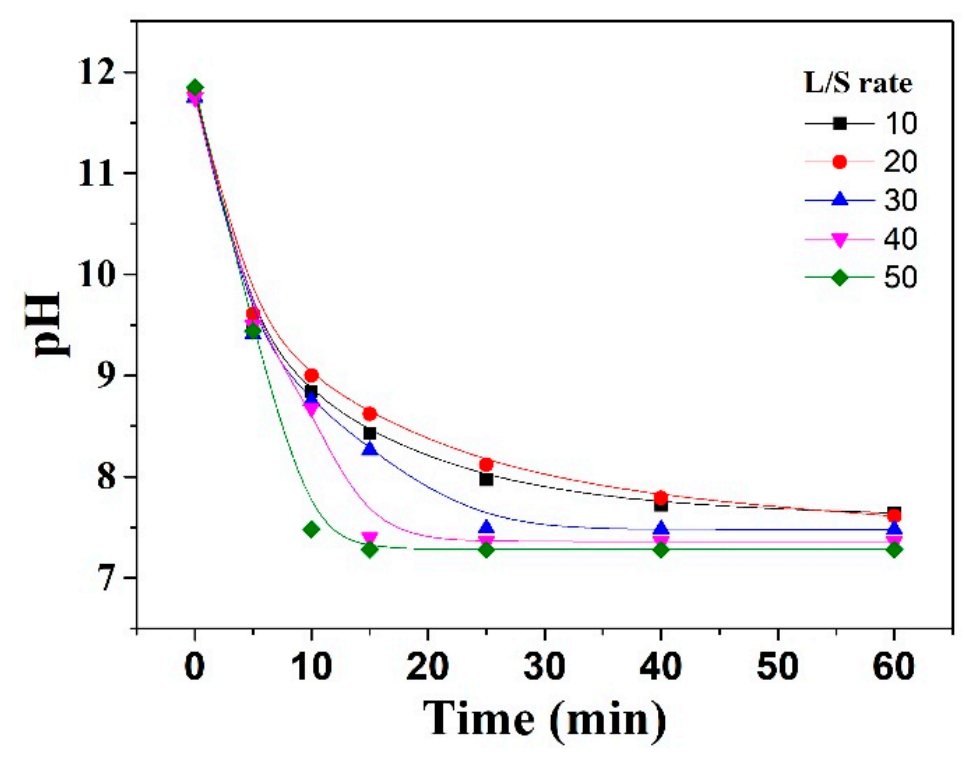

Figure 7. Variation of $\mathrm{pH}$ as a function of time.

\subsection{The Effect of Decomposition Conditions on Products}

As is shown in Figures 8 and 9, when the temperature increased from $60{ }^{\circ} \mathrm{C}$ to $90{ }^{\circ} \mathrm{C}$, the reaction rate and conversion rate of $\mathrm{LiHCO}_{3}$ increased significantly $[19,20]$. The decomposition process of the $\mathrm{LiHCO}_{3}$ solution is an endothermic reaction, so its equilibrium is shifted to the product side with increasing temperatures and promotes the solute diffusion and crystal growth rate. In conclusion, it is beneficial for both the decomposition of $\mathrm{LiHCO}_{3}$ and the crystallization of $\mathrm{Li}_{2} \mathrm{CO}_{3}$ to increase the operating temperature.

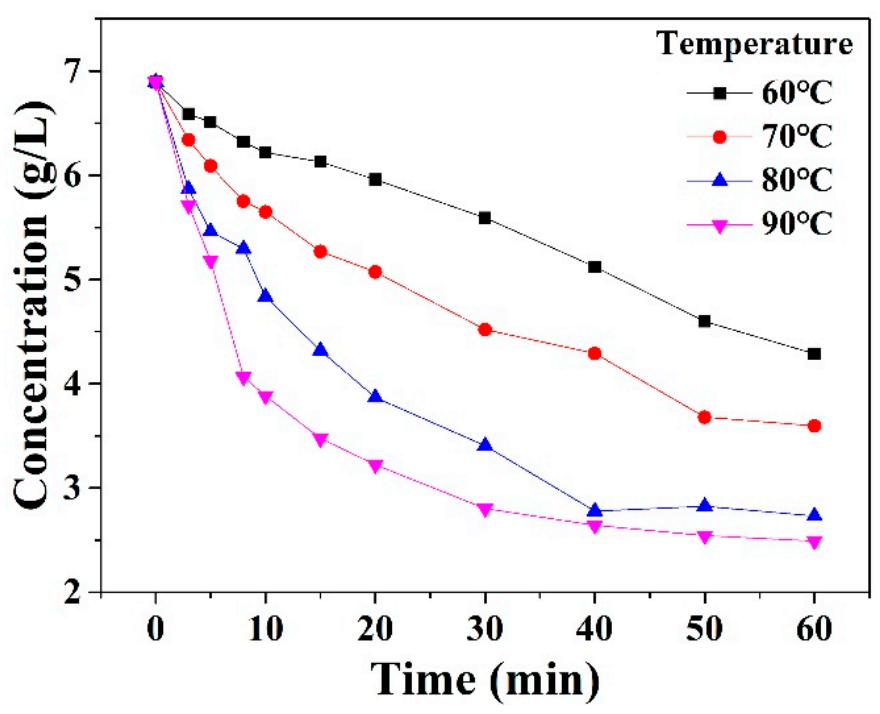

Figure 8. Effect of temperature on thermal decomposition crystallization [agitation speed $=300 \mathrm{rpm}$ ]. 


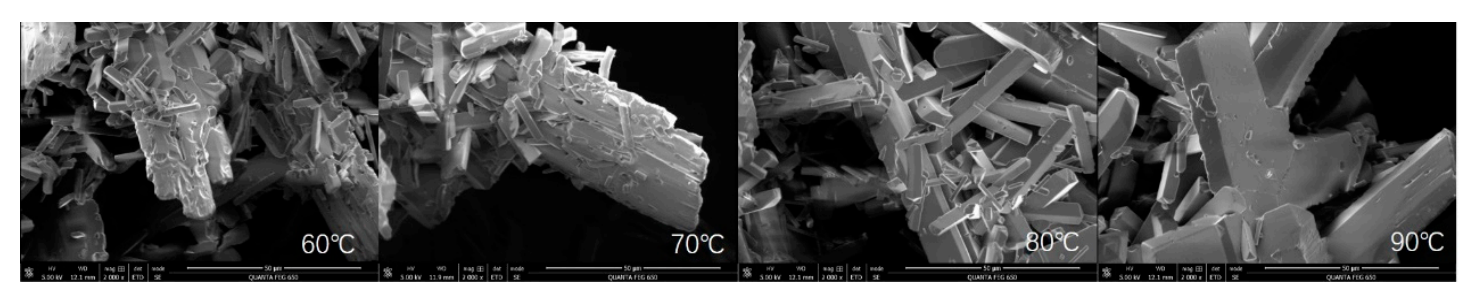

Figure 9. Sem-analysis of products under different temperatures.

Agitation speed is also one of the factors that affect thermal decomposition reaction. The particle size distribution of the products under different agitation speeds was investigated as shown in Figure 10. It can be seen that with the increase in agitation speed, the single crystal peak shifts to the left, and the height of the coalescence peak increased. It can be explained that with the increase in agitation speed, both the liquid turbulence intensity and the interface updating speed were increased. It was conducive to the diffusion of lithium carbonate solute and the growth of crystal surface and improving the crystal-crushing effect at the same time.

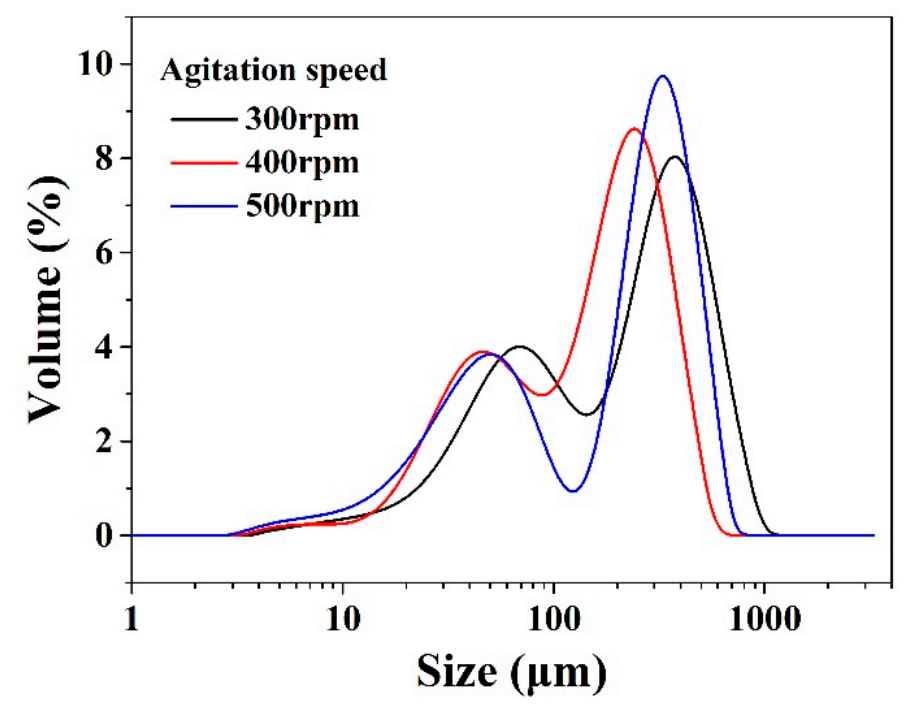

Figure 10. Effect of agitation speed on thermal decomposition crystallization [temperature $=90{ }^{\circ} \mathrm{C}$ ]

It is difficult to make the product directly meet the particle size requirement of batterygrade lithium carbonate by stirring and seed addition. In this paper, airstream pulverization was used to treat the product. The pulverizing effect of the jet mill under different air compressor pressures was studied as shown in Figure 11. The average particle size of the product decreased with the increase in air compressor pressure. The jet mill ejects the compressed gas at a high speed through the nozzle. The high-speed airflow brought the material to the crushing chamber where the particles were crushed by collision, friction, and shear. The air compressor pressure affects the air velocity, which affects the impact strength of the particles, and the product with different particle size distribution was obtained. 


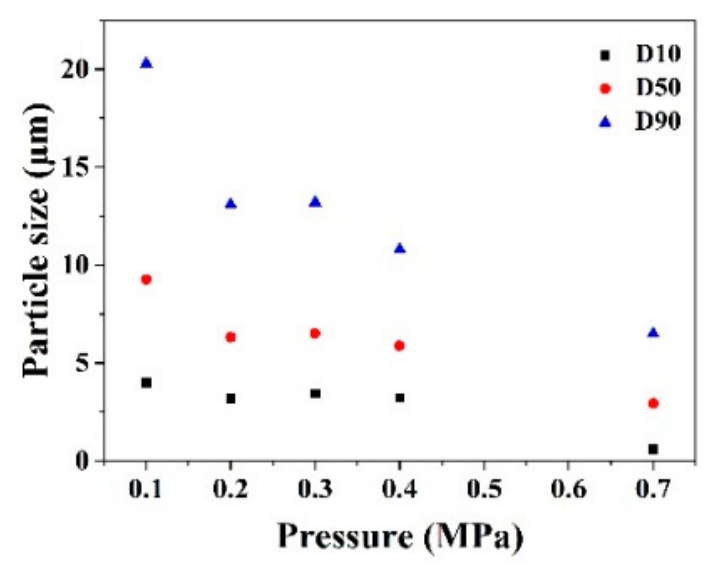

(a)

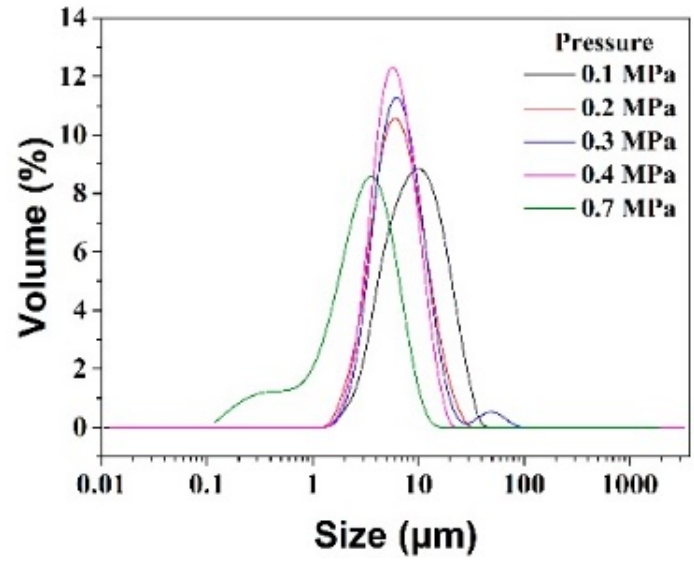

(b)

Figure 11. Effect of pressure on particle size. (a) average particle size (b) particle size distribution.

\section{Conclusions}

A carbonization-decomposition process was developed to produce battery-grade $\mathrm{Li}_{2} \mathrm{CO}_{3}$ from a lithium-containing desorption solution. The best reaction conditions were obtained: a liquid-solid ratio of $25: 1$, a carbonization temperature of $25^{\circ} \mathrm{C}$, an air velocity of $2 \mathrm{~L} / \mathrm{min}$, a carbonization time of $2 \mathrm{~h}$, and a stirring speed of $400 \mathrm{rpm}$. And the product finally reaches the battery-grade lithium carbonate battery-grade standard by air-jet crushing. The lithium content of the lithium carbonate product obtained through the three-step reaction reaches $99.6 \%$, the content of iron and aluminum in the product is less than $0.001 \%$, contents of other impurities are below the battery-grade lithium carbonate standard, the total yield of the product is about $70 \%$. The particle size of the lithium carbonate product can be controlled by changing the pressure of the jet mill to achieve the battery-grade standard requirement. The entire process has great industrial potential.

Author Contributions: Literature search, figures, study design, data collection, data analysis, and writing — original draft preparation and review, Z.-G.X.; methodology, data analysis, and writing—review and editing, S.-Y.S. All authors read and approved the final manuscript.

Funding: This research was funded by the National Key R\&D Program of China (2017YFB0603104), and Sponsored by Shanghai Pujiang Program (2019PJD011).

Institutional Review Board Statement: Not applicable.

Informed Consent Statement: Not applicable.

Data Availability Statement: Not applicable.

Acknowledgments: The research was supported by the National Key R\&D Program of China (2017YFB0603104), and Sponsored by the Shanghai Pujiang Program (2019PJD011).

Conflicts of Interest: The authors declare no conflict of interest. The funders had no role in the design of the study; in the collection, analyses, or interpretation of data; in the writing of the manuscript, or in the decision to publish the results.

\section{References}

1. Watamura, H.; Marukawa, H.; Hirasawa, I. Polyelectrolyte effects on the crystallization phenomena of the lithium carbonate. Cryst. Growth 2013, 373, 111-117. [CrossRef]

2. Zhao, C.; Zhang, Y.; Cao, H.; Zheng, X.; Van Gerven, T.; Hu, Y.; Sun, Z. Lithium carbonate recovery from lithium-containing solution by ultrasound assisted precipitation. Ultrason. Sonochem. 2018, 52, 484-492. [CrossRef] [PubMed]

3. Tian, M.; Wang, Z.; Cao, J.; Guo, J.; Gong, X. Insight into Lithium Carbonate Crystallization in the Mild Reaction System LiCl-NH $3 \cdot \mathrm{H}_{2} \mathrm{O}-\mathrm{CO}_{2}$ by Stabilizing the solution with $\mathrm{NH}_{3} \cdot \mathrm{H}_{2} \mathrm{O}$. Cryst. Growth 2019, 520, 46-55. [CrossRef]

4. Tian, M.; Guo, J.; Wang, Z.; Cao, J.; Gong, X. Synergetic effect of secondary nucleation and growth on the lithium carbonate particle size in the gas-liquid reactive crystallization of $\mathrm{LiCl}-\mathrm{NH}_{3} \cdot \mathrm{H}_{2} \mathrm{O}-\mathrm{CO}_{2}$. Particuology 2020, 51, 10-17. [CrossRef] 
5. Yi, W.T.; Yan, C.Y.; Ma, P.H.; Wen, X.M. Refining of crude $\mathrm{Li}_{2} \mathrm{CO}_{3}$ via slurry phase dissolution using CO 2 . Sep. Purif. Technol. 2007, 56, 241-248. [CrossRef]

6. Sun, Y.; Song, X.; Jin, W.; Yan, L.; Yu, J. Unseeded Supersolubility of Lithium Carbonate: Experimental Measurement and Simulation with Mathematical Models. Cryst. Growth 2009, 311, 4714-4719. [CrossRef]

7. Pan, X.; Dou, Z.H.; Zhang, T.A.; Meng, D.L.; Han, X.X. Basic study on direct preparation of lithium carbonate powders by membrane electrolysis. Hydrometallurgy 2020, 191, 105193. [CrossRef]

8. Yang, W.; Zhou, L.; Dai, J.; Zhou, L.; Yin, Q. Crystallization of Lithium Carbonate from Aqueous Solution: New Insights into Crystal Agglomeration. Ind. Eng. Chem. Res. 2019, 58, 18448-18455. [CrossRef]

9. Wang, W.; Chen, W.; Liu, H. Hydrometallurgical preparation of lithium carbonate from lithium-rich electrolyte. Hydrometallurgy 2019, 185, 88-92. [CrossRef]

10. Han, B.; Louhi-Kultanen, M. Lithium carbonate precipitation by homogeneous and heterogeneous reactive crystallization. Hydrometall. 2020, 195, 105386. [CrossRef]

11. Linneen, N.; Bhave, R.; Woerner, D. Purification of industrial grade lithium chloride for the recovery of high purity battery grade lithium carbonate. Sep. Purif. Technol. 2019, 214, 168-173. [CrossRef]

12. Zhu, C.; Dong, Y.; Yun, Z.; Hao, Y.; Wang, C.; Dong, N.; Li, W. Study of lithium exploitation from carbonate subtype and sulfate type salt-lakes of Tibet. Hydrometallurgy 2014, 149, 143-147. [CrossRef]

13. Martin, G.; Schneider, A.; Voigt, W.; Bertau, M. Lithium extraction from the mineral zinnwaldite: Part II: Lithium carbonate recovery by direct carbonation of sintered zinnwaldite concentrate. Miner. Eng. 2017, 110, 75-81. [CrossRef]

14. Xu, Z.; Zhang, H.; Wang, R. Systemic and Direct Production of Battery-Grade Lithium Carbonate from a Saline Lake. Ind. Eng. Chem. Res. 2014, 53, 16502-16507. [CrossRef]

15. Yi, W.T.; Yan, C.Y.; Ma, P.H. Removal of calcium and magnesium from $\mathrm{Li}_{2} \mathrm{HCO}_{3}$ solutions for preparation of high-purity $\mathrm{Li}_{2} \mathrm{CO}_{3}$ by ion-exchange resin. Desalination 2009, 249, 729-735. [CrossRef]

16. Xu, Z.G.; Wang, X.C.; Sun, S.Y. Performance of a Synthetic Resin for Lithium Adsorption in Waste Liquid of Extracting Aluminum from Fly-Ash. Chin. Chem. Eng. 2021. [CrossRef]

17. Shaojun, D.; Yuzhu, S.; Xingfu, S. Study on Preparation of Lithium Carbonate Via Reactive Crystallization from Old Salt Brine. Shandong Chem. Ind. 2018, 47, 5-8.

18. Weijun, L.B. Process analysis and mechanism discussion of enhanced COsequestration by mineral carbonation. Chem. Ind. Eng. Soc. China 2009, 60, 2332-2338.

19. Aghajanian, S.; Koiranen, T. Dynamic modeling and semibatch reactive crystallization of calcium carbonate through $\mathrm{CO}_{2}$ capture in highly alkaline water. $\mathrm{CO}_{2}$ Util. 2020, 38, 366-374. [CrossRef]

20. Yi, W.T.; Yan, C.Y.; Ma, P.H. Crystallization kinetics of $\mathrm{Li}_{2} \mathrm{CO}_{3}$ from $\mathrm{LiHCO}_{3}$ solutions. Cryst. Growth 2010, 312, 2345-2350. [CrossRef] 